\title{
Non-coeliac gluten sensitivity
}

\author{
Anonymous patient ${ }^{1}$, Kamran Rostami consultant physician ${ }^{2}$, Sabine Hogg-Kollars PhD student ${ }^{3}$ \\ ${ }^{1}$ Worcester, UK; ${ }^{2}$ Department of Gastroenterology, Mid Staffordshire NHS Foundation Trust, Stafford, UK; ${ }^{3}$ School of Cancer Sciences, Department \\ of Medical and Dental Sciences, University of Birmingham, Birmingham, UK
}

This is one of a series of occasional articles by patients about their experiences that offer lessons to doctors. The BMJ welcomes contributions to the series. Please contact Peter Lapsley (plapsley@bmj.com) for guidance.

\section{Abstract \\ This patient reflects on his 20 years of unexplained ill health with multiple symptoms before a chance conversation in an internet chat room led to his initial self diagnosis}

The summer of 1991 was when my problems really began. I had had a severe bout of sickness and diarrhoea on holiday in Corfu. I recovered from the gut infection after I came back from holiday, but my general health continued to deteriorate over the next six to 12 months.

Then followed two decades of unexplained ill health with multiple symptoms including weakness, exhaustion, bloating, nausea, indigestion, diarrhoea, skin rashes, ingrown hairs, cracked skin, joint and muscle pain, anal leakage of undigested fat, oscillating body weight, numbness in my feet and hands, muscle spasms in my legs (especially at night), mood swings, mild depression, and disturbed sleep patterns. These symptoms fluctuated day to day, but the worst by far was a constant intense bladder pain that was eventually diagnosed as incurable and untreatable interstitial cystitis.

My interstitial cystitis has been examined by biopsy, and I have undergone many many other urinary tests over $10-15$ years, including passing a camera into my bladder and inflating the bladder with fluid to watch for the classic "bleed" from the bladder wall when it is distended. My eventual diagnosis in Oxford was by a consultant in genitourinary medicine who specialises in interstitial cystitis and was a diagnosis of exclusion after all other possibilities had been eliminated. Diagnosis by exclusion is the norm for interstitial cystitis.

I received drug treatment for the interstitial cystitis, but my symptoms did not improve until I excluded gluten and lactose. They are now much better but not entirely eliminated. I eventually gave up my career, and, without the unfailing support of my wife, it would have ruined my life.
I now know that all of these symptoms stem from an intolerance or sensitivity to gluten that does not manifest itself as classic coeliac disease but which still causes many of the same bowel symptoms and can trigger other autoimmune conditions such as arthritis, interstitial cystitis, and neurological conditions (including pins and needles and numbness). Over the next 20 years, I repeatedly told medical professionals that my bladder pain was always much worse when my bowel symptoms were particularly bad and that the two must be linked. Most importantly, I felt strongly that it was caused by something I was eating. In particular, I had noticed that when I had either starved myself for 24 hours or undergone a bowel cleanse before a medical procedure my symptoms seemed to disappear or were much reduced.

Medical professionals seemed mystified or dismissive and had no explanation. I well remember being told by one consultant that there was nothing that could link bowel symptoms to bladder symptoms or any other symptom I had. Another young consultant told me that people with symptoms like mine often commit suicide. I'm fairly sure he wasn't suggesting it as a treatment option, but I certainly did feel very down about my condition.

Eventually, after about a decade, I gave up seeking a cure or diagnosis of my illness. I tried to live life as best and as fully as I could. By now I had two young children, and I tried to focus on the positives and counted my blessings. However, in Christmas 2006 I had a severe bout of biliary colic and eventually had my gall bladder removed (yet another condition I now know may be linked to gluten sensitivity), but my health continued to deteriorate after the operation.

By summer 2008, I was unable to walk up a hill and was gradually becoming house bound. The internet became an important link to the outside world, and I began a desperate search for some clue as to what was wrong with me. A chance conversation in a chat room forum with someone who had had exactly my symptoms and the suggestion that I try excluding gluten (and lactose) from my diet was how I eventually reached my own initial self diagnosis. The results were dramatic. Within a week of excluding gluten and lactose from my diet, all my 
symptoms had dramatically improved in just the same way as when I previously starved myself. I wasn't starving myself now though, I was just not eating gluten and lactose. I felt better and had more energy than I had in decades.

I went to see the consultant who had carried out the gall bladder operation and excitedly told him about my discovery that gluten and lactose were the source of all my health problems and how dramatic had been the results of excluding them from my diet even after a few weeks. He seemed quite uninterested but told me to carry on with the gluten and lactose exclusion diet "if you find it is working for you."

After experimenting with my diet, I have found that I react severely to even small traces of both gluten and lactose. Accidental exposure to either of them brings all my symptoms back in a matter of hours, and the symptoms take several days to subside again. I can almost always identify the source of the accidental exposure, and it happens very rarely now as my experience and knowledge of my condition and food ingredients have increased.

Despite the success with my exclusion diet, it wasn't until early 2012 that I finally got a proper diagnosis of my condition. After a chance internet search, I found medical research papers on gluten sensitivity and intolerance written by Dr Kamran Rostami. I have a degree in biochemistry, and those papers were a revelation. From my own personal experience and from the point of view of my training as a scientist, his papers made complete sense of everything that I had experienced. I had no idea that there was such a large and growing body of people expressing a wide spectrum of symptoms that seem to be linked to gluten intolerance and sensitivity but who did not exhibit classic coeliac disease. Like me, many of them had remained undiagnosed for years.

I immediately asked my GP to get me an appointment with Dr Rostami, who, unbeknown to me, was working just a few miles away in my local hospital. Before Dr Rostami, no medical professional had ever said the word "gluten" to me over the entire 20 years of my ill health. However, I don't feel bitter about the medical practitioners who failed to diagnose my health problems. Each was highly skilled in his or her own specialty, but nobody was looking at the whole picture. A specialist in chronic bladder pain is not a specialist in gastrointestinal medicine.

As a result of my conversations with Dr Rostami, I strongly suspect that my problems with gluten really began long before 1991 and that the gut infection I had on holiday was simply a trigger that made my gut more permeable to gluten (and lactose) and eventually caused the emergence of more severe symptoms. Looking back, it is clear to me that I exhibited early signs of gluten intolerance and sensitivity in my childhood. I weighed under 6 stone $(38 \mathrm{~kg}$ ) when I was 12 years old. In 1991 I weighed about $11 \mathrm{st} 7 \mathrm{lb}(73 \mathrm{~kg}$ ), but after my symptoms started, my weight fell to under $11 \mathrm{st}(70 \mathrm{~kg})$ and I felt very weak. Then my weight ballooned up to $13 \mathrm{st} 7 \mathrm{lb}(86 \mathrm{~kg})$ after my gall bladder was removed in 2008. Finally, after I had excluded gluten, it fell to $11 \mathrm{st} 4 \mathrm{lb}$ over a few months, where it remains today. To be honest, the most important issue with my weight is that it can easily rise $4-7 \mathrm{lb}(2-3 \mathrm{~kg})$ overnight if I accidentally eat gluten, as I fill up with fluid when my immune system goes into overdrive.
I had mild depression throughout my teenage years, was small and underweight, and went through puberty later than the other boys in my class at school. I also used to gorge on bread, cakes, and biscuits, but I was always thin despite the thousands of calories I was eating. I have read that it is common for people to be addicted to the foodstuff that does them most harm. That was certainly true in my case. Paradoxically, as the son of a farmer and growing up on a farm, I used to help my father grow wheat, and he was paid a higher price by merchants if he could grow wheat with high levels of gluten for bread and biscuit making. Like my father, I used to chew the wheat grains at harvest time to check for hardness as we decided when to harvest the crop. Every year I got itchy bleeding rashes on my ankles and elbows that went away as soon as harvest finished. Now I know why.

\section{Competing interests: All authors declare no support from any} organisation for the submitted work; no financial relationships with any organisations that might have an interest in the submitted work in the previous three years; no other relationships or activities that could appear to have influenced the submitted work.

Provenance and peer review: Not commissioned; not externally peer reviewed.

1 Sapone A, Bai JC, Ciacci C, Dolinsek J, Green PH, Hadjivassiliou M, et al Spectrum of gluten-related disorders: consensus on new nomenclature and classification. BMC Med 2012;10:13.

2 Brottveit M, Vandvik PO, Wojniusz S, Løvik A, Lundin KE, Boye B. Absence of somatization in non-coeliac gluten sensitivity. Scand J Gastroenterol 2012;47:770-7.

3 Ludvigsson JF, Leffler DA, Bai JC, Biagi F, Fasano A, Green PH et al The Oslo definitions for coeliac disease and related terms. Gut 2012 Feb 16 (epub ahead of print).

4 Volta U, De Giorgio R. New understanding of gluten sensitivity. Nat Rev Gastroenterol Hepatol 2012;9:295-9.

5 Di Sabatino A, Corazza GR. Nonceliac gluten sensitivity: sense or sensibility? Ann Intern Med 2012;156:309-11.

6 Brown AC. Gluten sensitivity: problems of an emerging condition separate from celiac disease. Expert Rev Gastroenterol Hepatol 2012;6:43-55.

7 Volta U, Tovoli F, Cicola R, Parisi C, Fabbri A, Piscaglia M, et al. Serological tests in gluten sensitivity (nonceliac gluten intolerance). J Clin Gastroenterol 2012;46:680-5.

8 Troncone R, Jabri B. Coeliac disease and gluten sensitivity. J Intern Med 2011;269:582-90.

9 Pallav K, Leffler DA, Tariq S, Kabbani T, Hansen J, Peer A, et al. Noncoeliac enteropathy: the differential diagnosis of villous atrophy in contemporary clinical practice. Aliment Pharmacol Ther 2012;35:380-90

10 Sapone A, Lammers KM, Mazzarella G, Mikhailenko I, Cartenì M, Casolaro V, et al. Differential mucosal IL-17 expression in two gliadin-induced disorders: gluten sensitivity and the autoimmune enteropathy celiac disease. Int Arch Allergy Immunol 2010:152:75-80.

11 Biesiekierski JR, Newnham ED, Irving PM, Barrett JS, Haines M, Doecke JD, et al. Gluten causes gastrointestinal symptoms in subjects without celiac disease: a double-blind randomized placebo-controlled trial. Am J Gastroenterol 2011;106:508-14.

12 Kaukinen K, Turjanmaa K, Mäki M, Partanen J, Venäläinen R, Collin P et al. Intolerance to cereals is not specific for coeliac disease. Scand J Gastroenterol 2000;35:942-6

13 Jackson JR, Eaton WW, Cascella NG, Fasano A, Kelly DL. Neurologic and psychiatric manifestations of celiac disease and gluten sensitivity. Psychiatr Q 2012;83:91-102.

14 Bizzaro N, Tozzoli R, Villalta D, Fabris M, Tonutti E. Cutting-edge issues in celiac disease and in gluten intolerance. Clin Rev Allergy Immunol 2012;42:279-87.

15 Ostblom E, Wickman M, van Hage M, Lilja G. Reported symptoms of food hypersensitivity and sensitization to common foods in 4-year-old children. Acta Paediatr 2008:97:85-90.

16 Ferch CC, Chey WD. Irritable bowel syndrome and gluten sensitivity without celiac disease: separating the wheat from the chaff. Gastroenterology 2012;142:664-6.

17 Wahnschaffe U, Ullrich R, Riecken EO, Schulzke JD. Celiac disease-like abnormalities in a subgroup of patients with irritable bowel syndrome. Gastroenterology 2001;121:1329-38

18 Rostami Nejad M, Hogg-Kollars S, Ishaq S, Rostami R. Subclinical celiac disease and gluten sensitivity. Gastroenterol Hepatol Bed Bench 2011;4:102-8.

19 Tatham AS, Shewry PR. Allergens in wheat and related cereals. Clin Experiment Aller 2008;38:1712-26.

20 Inomata N. Wheat allergy. Cur Opin Aller Clinic Immunol 2009;9:238-43.

21 Tucker E, Rostami K, Prabhakaran S, Al Dulaimi D. Patients with coeliac disease are increasingly overweight or obese on presentation. J Gastrointestin Liver Dis 2012;21:11-5.

Accepted: 23 October 2012

Cite this as: BMJ 2012;345:e7982

(c) BMJ Publishing Group Ltd 2012 


\section{A clinician's perspective}

The definition of non-coeliac gluten sensitivity goes back to 1986, and there are sporadic reports of this entity but not as strong as in the past few years. Interest has increased after recent advances enabling us to make a clear differentiation between coeliac disease and gluten sensitivity. ${ }^{1-4}$

It is now becoming clear that, besides those with coeliac disease or wheat allergy, there are patients with gluten sensitivity in whom neither allergic nor autoimmune mechanisms can be identified..$^{56}$ It has been estimated that, for every person with coeliac disease, there should be at least six or seven people with non-coeliac gluten sensitivity. Gluten sensitivity may therefore affect $6-10 \%$ of the general population. This means approximately $4-7$ million people in the United Kingdom have this condition, and the vast majority are unaware of their sensitivity to gluten. . $^{5-15}$

Patients with gluten sensitivity have negative immuno-allergy tests to wheat and negative coeliac disease serology; normal endoscopy and biopsy; clinical symptoms that can overlap with those of coeliac disease, irritable bowel syndrome, and wheat allergy; and they show a resolution of symptoms when started on a gluten-free diet. ${ }^{16-20}$

This patient's history is a classic example of severe gluten sensitivity. He describes how gluten has affected his digestive system, his skin, his nervous system muscles and joints, sleep, and mood, and even his so called incurable interstitial cystitis. I met the patient after a long history of ill health. He was frustrated with the lack of a diagnosis to explain his symptoms. He underwent gastroscopy and colonoscopy in 2009. Duodenal biopsy and serology for coeliac disease came back negative.

Despite being highly educated with a degree in biochemistry, he had to give up his career and wait for decades before being diagnosed with gluten sensitivity. This is disconcerting if we think about how many people are possibly experiencing similar symptoms, with the added drawback of poor health literacy. I greatly admire the way he managed to find a solution for the unresolved symptoms he had experienced for decades. Despite the fact that he responded well to a gluten-free diet, it was still important for him, as it is for most patients, to have a diagnosis that can explain the symptoms.

His weight was inversely related to his gluten intake. Although weight loss can be a feature of coeliac disease and gluten sensitivity, it is less common in atypical forms of both conditions. ${ }^{21}$

Currently there are no laboratory biomarkers specific for gluten sensitivity, and the diagnosis is based on exclusion criteria; elimination of gluten-containing foods from the diet followed by an open challenge is most often used to establish whether health improves with the elimination or reduction of gluten from the patient's diet. ${ }^{1-15}$ As rightly reflected in a recent $B M J$ editorial, increasing people's ability to understand and engage in their healthcare is an international priority. At the same time, however, educating healthcare professionals about this highly prevalent and under-recognised condition is strongly recommended. Kamran Rostami 